\title{
Bearing Capacity Estimation of Bridge Piles Using the Impulse Transient Response Method
}

\author{
Meng Ma, ${ }^{1}$ Jianlei Liu, ${ }^{2}$ Zaitian $\mathrm{Ke}^{2}$ and Yan Gao ${ }^{2}$ \\ ${ }^{1}$ School of Civil Engineering, Beijing Jiaotong University, Beijing 100044, China \\ ${ }^{2}$ Railway Engineering Research Institute, China Academy of Railway Sciences, Beijing 100081, China \\ Correspondence should be addressed to Meng Ma; mameng_02231250@163.com
}

Received 10 July 2015; Accepted 18 October 2015

Academic Editor: Mickaël Lallart

Copyright (c) 2016 Meng Ma et al. This is an open access article distributed under the Creative Commons Attribution License, which permits unrestricted use, distribution, and reproduction in any medium, provided the original work is properly cited.

\begin{abstract}
A bearing capacity estimation method for bridge piles was developed. In this method, the pulse echo test was used to select the intact piles; the dynamic stiffness was obtained by the impulse transient response test. A total of 680 bridge piles were tested, and their capacities were estimated. Finally, core drilling analysis was used to check the reliability of this method. The results show that, for intact piles, an obvious positive correlation exits between the dynamic stiffness and bearing capacity of the piles. The core drilling analysis proved that the estimation method was reliable.
\end{abstract}

\section{Introduction}

The ultimate capacity of a single pile is regarded as one of the most important issues in pile testing [1]. The static load test (SLT) is considered to be the most reliable method to evaluate the pile capacity; however, it can be expensive and time consuming. As a classic dynamic loading test method, the high-strain dynamic pile testing (HSDPT) is more economical and efficient than the SLT. The HSDPT tests deep foundations to obtain information about their capacity and integrity, and in some cases, to monitor their installation.

The low-strain dynamic test, also known as the pulse echo method (PEM), is a method that is usually used to check the integrity of the pile. The PEM is widely used [2-4] and recommended by many codes [5-8]. The transient response method (TRM), also known as the mechanical mobility method, is a method similar to the PEM and was proposed in the 1960s 1970s [9]. TRM analyses both the velocity and the force signals in the frequency domain. The velocity spectrum is divided by the force spectrum to determine the mobility or mechanical admittance spectrum [10], which helps provide more information compared to the PEM to identify defects near the top of the pile [11]. An idealised test graph of pile mobility versus frequency is shown in Figure 1. Some key information from the graph, such as the peak/mean mobility ratio, mobility, and damping, is widely used to evaluate the pile integrity and pile length [12-15]. Another important parameter from the curve was the dynamic stiffness $\left(K_{d}\right) . K_{d}$ is the slope of the low frequency (i.e., $<50 \mathrm{~Hz}$ ) linear portion of the graph from the origin to the first peak. This value is sensitive to the stiffness of the pile shaft under compression.

For practical engineering, the STL and HSDPT are not permitted for a bridge in service with a large number of piles. In this paper, because many piles with different defects were evaluated along a highway bridge with a length of approximately $20 \mathrm{~km}$, it is urgent to evaluate piles with insufficient capacity and reinforce them. Generally, the lowstrain dynamic test, especially the PEM, can only provide integrity information, so it should not be used as the sole factor in establishing pile acceptance or rejection [5]. In this paper, to provide a quantitative capacity estimation, the TRM is developed and includes three steps: (1) preanalysis, (2) general investigation measurement, and (3) check and verification. The TRM test is performed on all 680 piles. In the TRM test, a drop hammer weighing $106 \mathrm{~kg}$ was employed instead of a small hand hammer to excite the first natural frequency of the pile. The dynamic stiffness $K_{d}$ for each pile can be obtained from the TRM test. The PEM test is used as an assisting technique to select the piles with good integrity. Regular values of $K_{d}$ for intact piles can be found. 


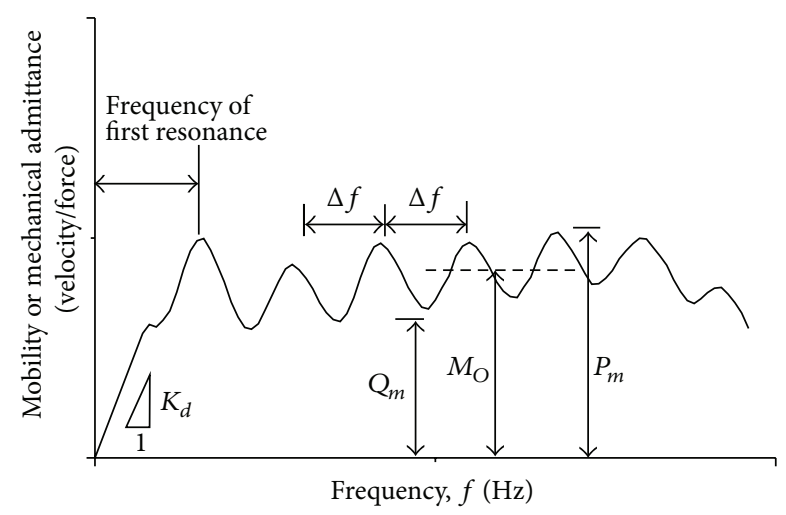

FIGURE 1: Idealised results of a vibration test by the TRM [8].

Accordingly, a pile may have a low capacity if its $K_{d}$ is obviously smaller than the regular values. Finally, the core drilling analysis is performed to check the estimation results.

\section{Capacity Estimation Method for Bridge Piles}

To estimate the bearing capacity for a large number of piles, the TRM was developed when the pile loading test and highstrain test were not allowed.

The dynamic stiffness $K_{d}$ can be calculated by

$$
K_{d}(f)=\frac{2 \pi f}{|V(f) / F(f)|},
$$

where $V(f)$ and $F(f)$ are the velocity and force signals in the frequency domain. When $f \rightarrow 0$, the value of the dynamic stiffness approaches the static stiffness, or $K_{d} \rightarrow K_{s}$. In practice, however, the frequency of the dynamic impulse cannot be $0 \mathrm{~Hz}$. Therefore, a coefficient $\alpha$ is introduced here to describe the ratio between the dynamic and static stiffness: $\alpha=K_{d} / K_{s}$. Then, the pile bearing capacity $Q$ can be calculated by

$$
Q=\frac{K_{d} S_{a}}{\alpha},
$$

where $S_{a}$ is the guideline value of the pile settlement.

To evaluate a large number of piles for a long highway bridge, the following three steps are proposed (Figure 2).

(1) Preanalysis. Some typical piles were selected to perform the TRM test and PEM integrity test. Then, the data of the intact piles are used to calculate $\alpha$. The value of $\alpha$ is adjusted dynamically.

(2) General Investigation Measurement. Measure all of the piles and calculate $Q$ by (1). Compare $Q$ with the design load $P$. If $Q>P$, the capacity is sufficient; otherwise, reinforcement of the pile is suggested.

(3) Checking and Verification. Verify the evaluation results by the PEM and pile core drilling.

To reduce the measurement and analysis errors, the height of the drop hammer and sensor location are the same in all of the TRM tests.

Because destructive loading tests are not allowed for existing piles, the designed allowable capacity is used as a rough estimation of the pile, assuming good integrity.

In the preanalysis step, the intact piles are selected using the PEM, and coefficient $\alpha$ was calculated by

$$
\alpha=\frac{K_{d} S_{a}}{\left[R_{a}\right]},
$$

where $\left[R_{a}\right]$ is designed allowable capacity, calculated by JTG D63-2007, "Code for Design of Ground Base and Foundation of Highway Bridges and Culverts" [16]. For cast-in-situ drilling friction piles, the capacity is expressed as

$$
\begin{aligned}
{\left[R_{a}\right] } & =\frac{1}{2} u \sum_{i=1}^{n} q_{i k} l_{i}+A_{p} q_{r} \\
q_{r} & =m_{0} \lambda\left[\left[f_{a 0}\right]+k_{2} \gamma_{2}(h-3)\right]
\end{aligned}
$$

and for cast-in-situ end-bearing piles, the bearing capacity can be expressed as

$$
\left[R_{a}\right]=c_{1} A_{p} f_{r k}+u \sum_{i=1}^{m} c_{2 i} h_{i} f_{r k i}+\frac{1}{2} \zeta_{s} u \sum_{i=1}^{n} l_{i} q_{i k},
$$

where $u$ is the perimeter; $A_{p}$ is the cross sectional area at the pile end; $n$ is the number of soil layers; $l_{i}$ is the thickness of the $i$ th soil layer; $q_{i k}$ is standard value of the lateral friction for the $i$ th soil; $q_{r}$ is the soil allowable capacity at the pile end; $\left[f_{a 0}\right]$ is the basic soil allowable capacity at the pile end; $h$ is the embedded depth of the pile end; $k_{2}$ is the revised coefficient of allowable capacity, which changes with depth; $\gamma$ is the weighted average unit weight; $f_{r k}$ is the standard value of the saturated uniaxial compressive strength of the rock at the pile end; $h_{i}$ is the thickness of the $i$ th rock layer; $m$ is the number of rock layers, in which strong and fully weathered rocks are not included but are considered to be a soil layer instead; and $\lambda, m_{0}, c_{1}, c_{2}$, and $\zeta_{s}$ are all coefficients, the guideline value of which can be obtained from the code.

To improve the calculation accuracy in (4) and (5), 48 soil samples were obtained from core drilling near different piers along the highway bridge. Figure 3 shows some typical soil samples.

With the small hammer (usually $<10 \mathrm{~kg}$ ) in the traditional PEM and TRM tests, the great mass of the pile cap absorbed most energy of the applied impact, so the amplitude of the reflected wave from the pile bottom was unclear and difficult to identify [17]. To solve this problem, in the TRM test, a drop hammer weighing $106 \mathrm{~kg}$ was used so that the input energy can excite the first natural frequency of the pile. In the PEM test, a hammer weighing $30 \mathrm{~kg}$ was used and the sensor was 


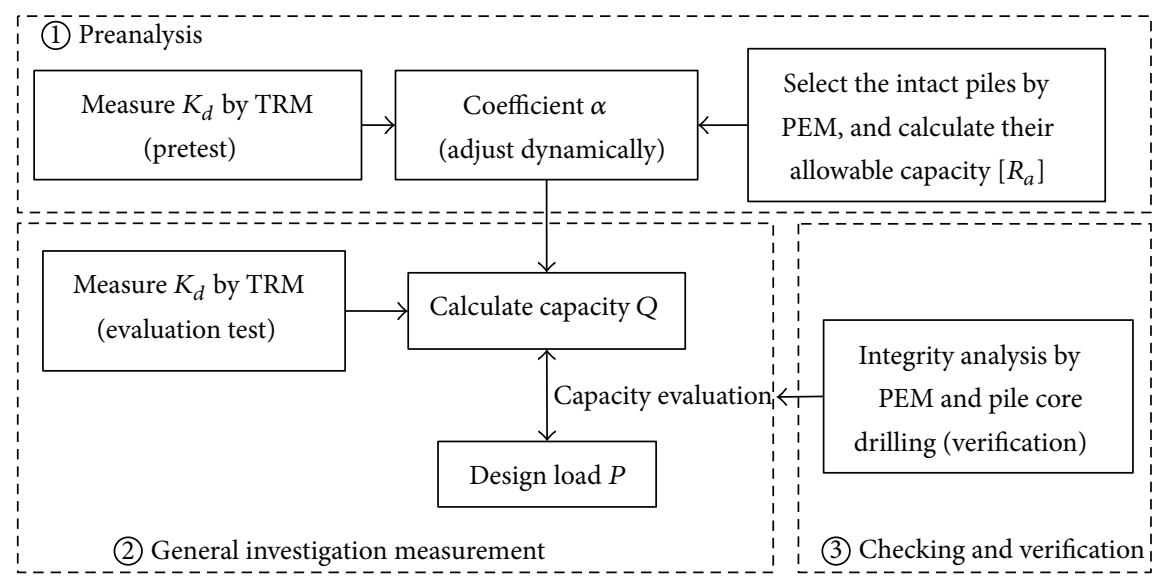

FIGURE 2: Flowchart of the bridge pile evaluation and analysis.

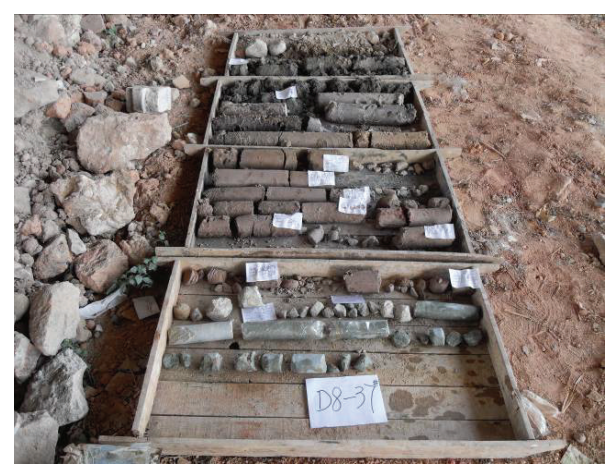

(a) Near Pier number D8-37

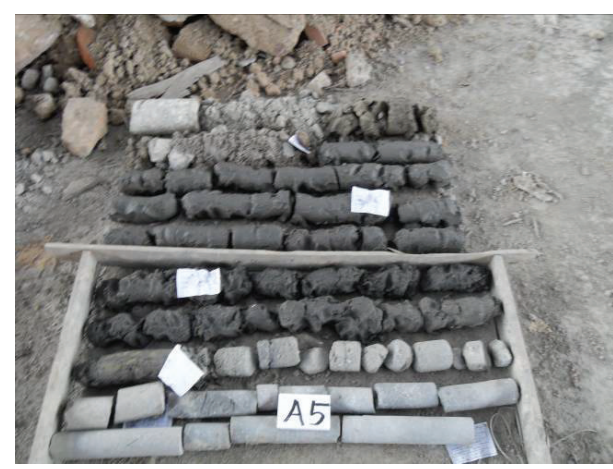

(b) Near Pier number H1-A5

FIgURE 3: Typical soil samples from core drilling.

installed directly on top of the pile by drilling on the cap, $50 \mathrm{~cm}$ from the bottom of the cap (Figure 4).

\section{Dynamic Measurement and Analysis}

3.1. Dynamic Stiffness. By analysing both the velocity and the force signals at the pile top in the frequency domain, the mobility can be calculated by

$$
G_{v}(f)=\frac{S_{F V}(f)}{S_{F F}(f)},
$$

where $S_{F V}(f)$ is the cross power spectrum between the force and velocity and $S_{F F}(f)$ is the auto power spectrum of the force.

Before measuring, clear the miscellaneous fill from the pile caps and polish the cap surface with an angle grinder (Figure 5) to ensure that the sensors collect the vertical signals.

Figure 6 shows the typical mobility responses of two neighbouring piles under the same cap. Similar curves below $50 \mathrm{~Hz}$ can be observed, which provide the basis for the dynamic stiffness analysis. Figure 7 shows the dynamic stiffness of the two piles. The steady value of $K_{d}$ can be found between 10 and $30 \mathrm{~Hz}$; therefore, the average $K_{d}$ was calculated between these frequencies for each pile.

3.2. Correlation between Dynamic Stiffness and Bearing Capacity. In total, 680 piles have been measured. The averaged dynamic stiffness was calculated from the measurements, and the allowable bearing capacity was estimated using (3) or (4) for each pile.

Figure 8(a) shows the relationship between the dynamic stiffness and estimated capacity. In general, the allowable capacity increases as dynamic stiffness increases. The measured samples were generally within $4 \sim 8 \mathrm{GN} / \mathrm{m}$; however, the allowable bearing capacity varied greatly. This was because the estimated capacity was based on the assumption that all of the piles were intact. In practice, different levels of defects were found for a large number of the piles. To eliminate this disadvantage, integrity tests were performed using the PEM, and then 188 typical integrated samples were selected and replotted in Figure 8(b). Then, a good positive relationship between the dynamic stiffness and bearing capacity was observed. Therefore, the dynamic stiffness can be used as an early warning for the capacity evaluation when the measured value is obviously low. 


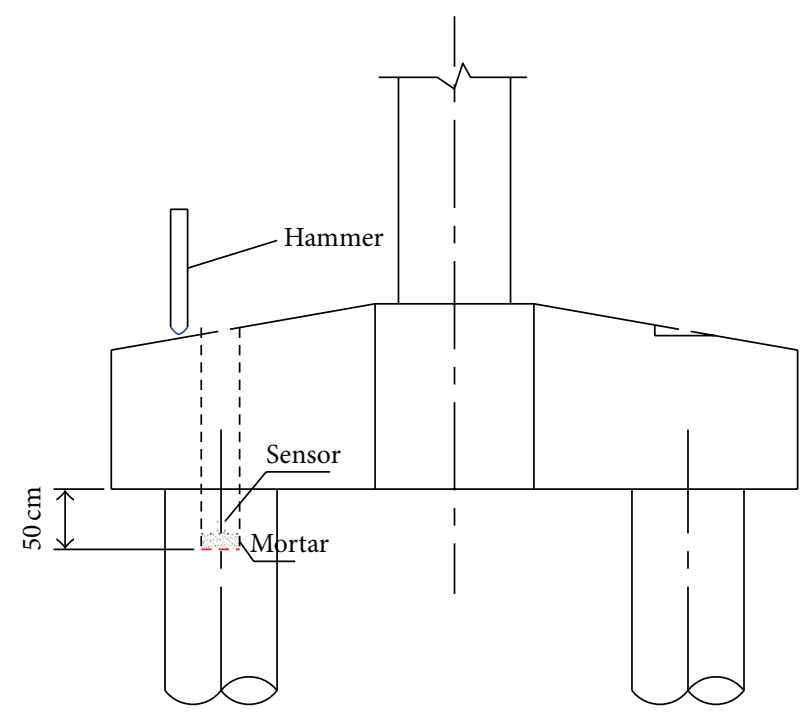

FIgURE 4: Sensor installed on top of the pile during the PEM test.

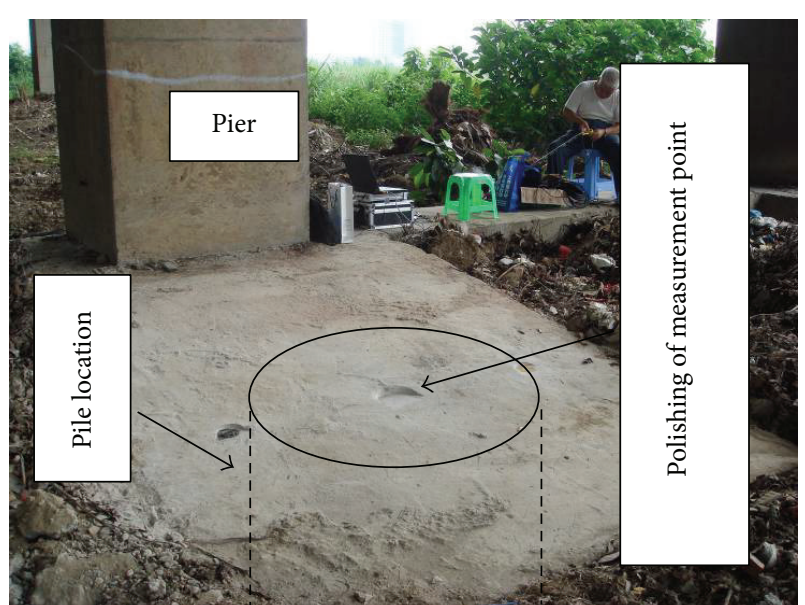

FIGURE 5: Surface polishing where the sensors are located.

3.3. Analysis of Coefficient $\alpha$. In the preanalysis step, coefficient $\alpha$ was calculated by (2) and adjusted dynamically. Finally, for friction piles and most end-bearing piles, the value of $\alpha$ was estimated to be 4.66 ; for very long end-bearing piles (length $>26 \mathrm{~m}$ ) the value of $\alpha$ was estimated to be 2.3.

The typical 188 intact pile samples (Figure 8(b)) were used to verify the estimation values of $\alpha$. The results are shown in Figure 9. One can observe that (1) more than $90 \%$ of the friction pile samples have a value of $\alpha$ smaller than 4.66, which ensures a safe estimation of the pile bearing capacity; (2) all of the end-bearing pile samples shorter than $26 \mathrm{~m}$ have an $\alpha$ smaller than 4.66; and (3) most of the end-bearing pile samples longer than $26 \mathrm{~m}$ have an $\alpha$ smaller than 2.3, except for four samples that have an $\alpha$ value that is slightly larger than 2.3. In general, the value of $\alpha$ estimated in the preanalysis step provides a good basis for the capacity evaluation of bridge piles.

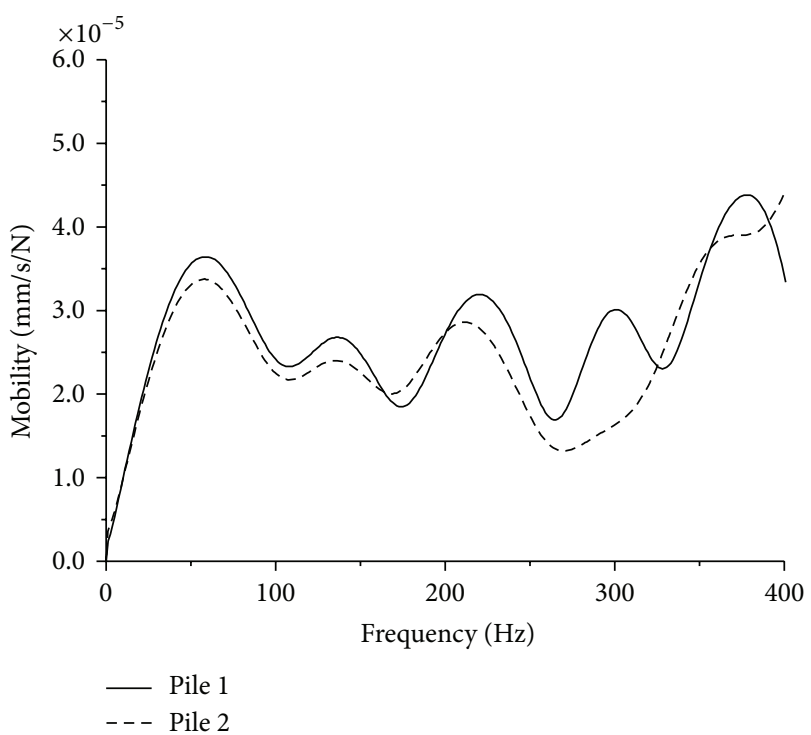

FIgURE 6: Typical mobility curves.

3.4. Evaluation of the Pile Bearing Capacity. The 680 piles were evaluated using the method introduced in Figure 2. Figure 10 shows the relation between the estimated bearing capacity $Q$ and design load $P$. Based on static analysis, approximately $54 \%$ of the piles need to be reinforced because $Q<P$, which occurred in different two cases. One case was caused by the large design load, which was approximately $8000 \mathrm{kN}$. The estimated capacity cannot bear this large load, although these piles are intact and without defects. The other case was caused by different types of pile defects. The measured low dynamic stiffness of these piles, the design loads of which were between 4000 and $5000 \mathrm{kN}$, led to a low estimated capacity. 


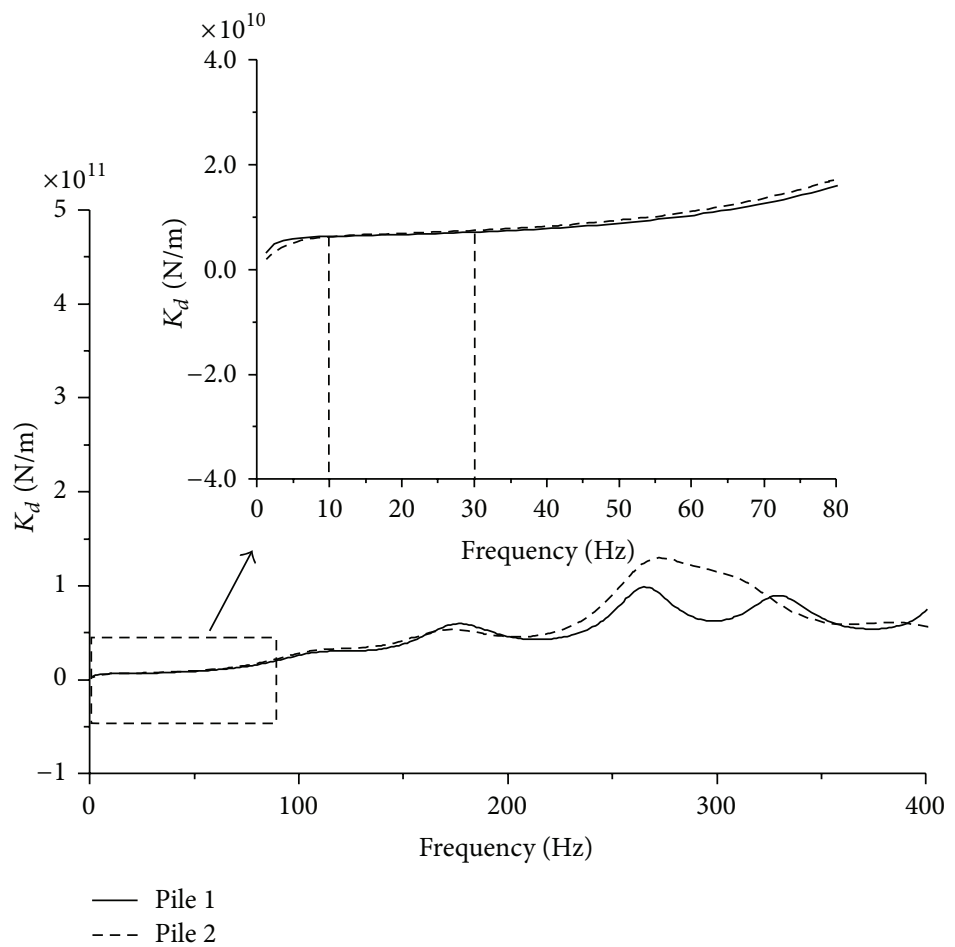

FIGURE 7: Typical dynamic stiffness curves.

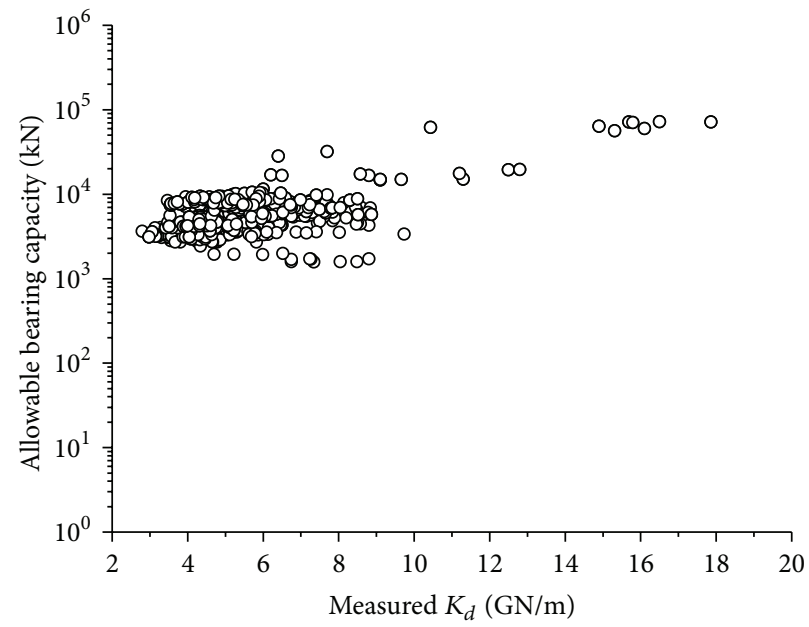

(a)

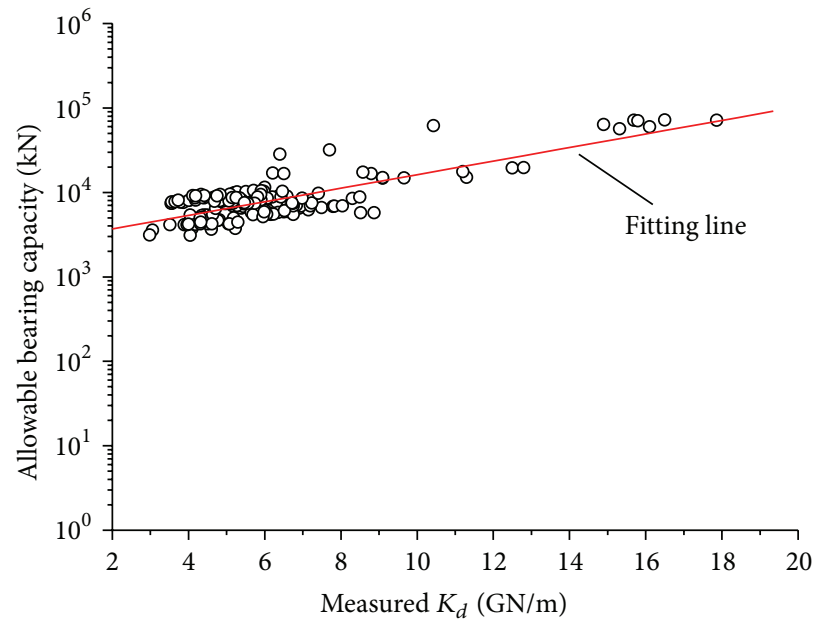

(b)

FIGURE 8: The relation between the dynamic stiffness and bearing capacity: (a) for all piles (680 samples) and (b) for typical intact piles (188 samples).

Further analysis of the piles with the design loads between 4000 and $5000 \mathrm{kN}$, as shown in Figure 11, shows that the dynamic stiffness of the piles with insufficient capacities was obviously lower than the piles with sufficient capacities. Therefore, the dynamic stiffness, as an evaluation descriptor, plays a beneficial role in evaluating piles of the same type and similar design load.

\section{Core Drilling Analysis}

To validate the estimation method proposed in this paper, 80 random pile samples were used to perform the core drilling analysis. Based on the integrity and defects of the core drilling samples, different classes from A to I were defined. A detailed description of the classes is listed in Table 1 by the aspects of the pile concrete, necking, segregation, and other defects. 


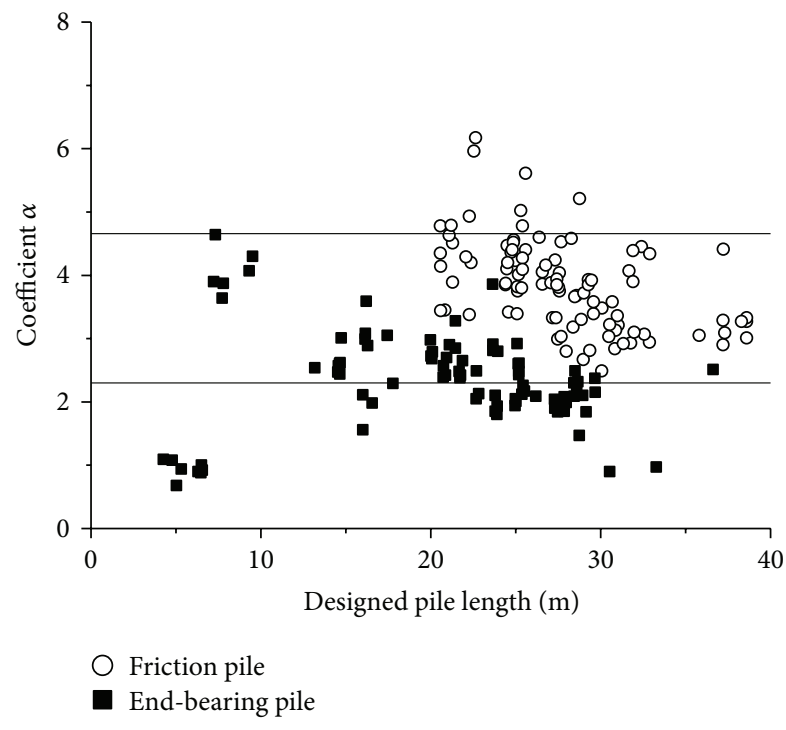

Figure 9: Typical coefficient $\alpha$ of bridge piles (188 samples).

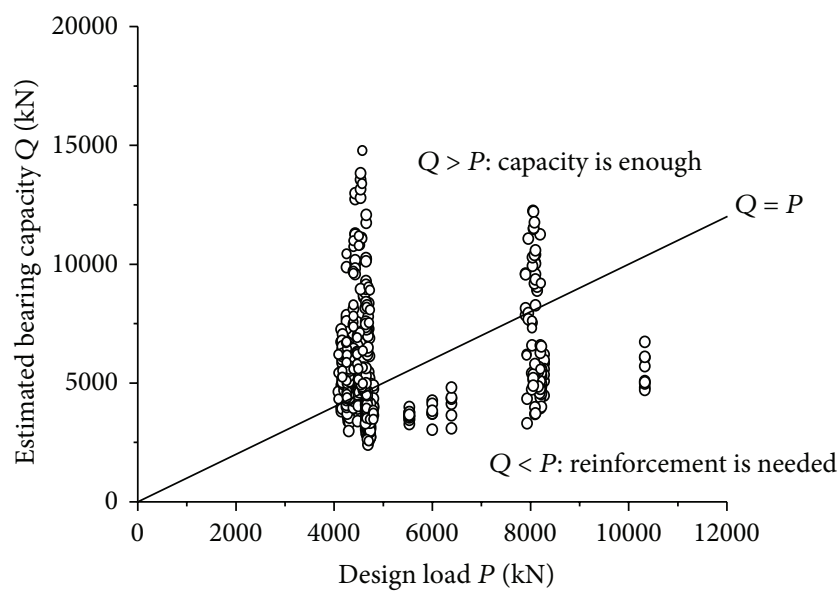

FIGURE 10: Relationship between the calculated bearing capacity and bearing design load (680 samples).

The sample number for each class was also counted and plotted in Figure 12. Pictures of typical core drilling samples are shown in Figure 13. In general, a smaller value of $Q / P$ relates to more obvious defects and poor integrity in the drilling samples. There were 45 piles with high necking or segregation, which accounts for $88.2 \%$ of the 51 piles with a value of $Q / P<1$. There were 21 piles without necking and segregation, which accounts for $72.4 \%$ of the 29 piles with a value of $Q / P<1$. The above core drilling analysis shows similar estimation results, which shows that the estimation method for the pile bearing capacity is reliable.

\section{Conclusions}

(1) The dynamic stiffness obtained from the pile mobility curve is a sensitive index under compression load.

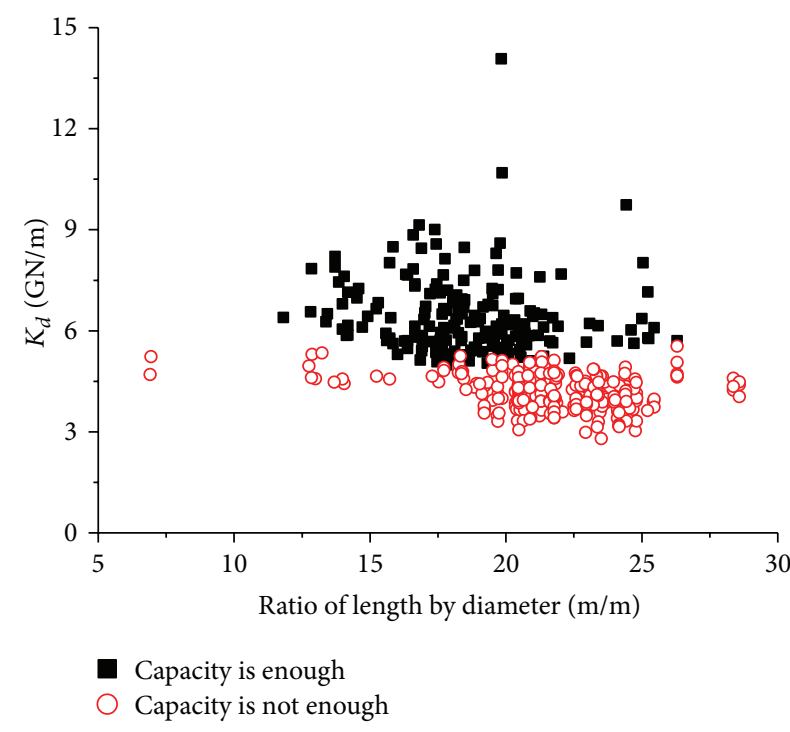

FIgURE 11: Dynamic stiffness of the friction piles.

TABle 1: Classification of the pile quality.

\begin{tabular}{lcccc}
\hline Class & Pile concrete & Necking & Segregation & $\begin{array}{c}\text { Other } \\
\text { defects }\end{array}$ \\
\hline A & Loose and poor & - & High & - \\
B & Fine & Middle & High & - \\
C & Fine & Low & Low & $\begin{array}{c}\text { Bad joint } \\
\text { with pile } \\
\text { cap }\end{array}$ \\
D & Fine & High & - & - \\
E & Good & - & Middle & $\begin{array}{c}\text { Low toe } \\
\text { debris }\end{array}$ \\
F & Good & - & Low & - \\
G & Good & - & - & Toe debris \\
H & Good & - & - & - \\
I & Good & - & - & $\begin{array}{c}\text { Partly } \\
\text { surface pore }\end{array}$ \\
\hline
\end{tabular}

(2) For intact piles, an obvious positive correlation is found between the dynamic stiffness and bearing capacity of the piles.

(3) The values of the dynamic stiffness are good for evaluating the bearing capacity of piles when they bear similar design loads. The core drilling analysis proved that the estimation method was reliable.

\section{Conflict of Interests}

The authors declare that there is no conflict of interests regarding the publication of this paper. 


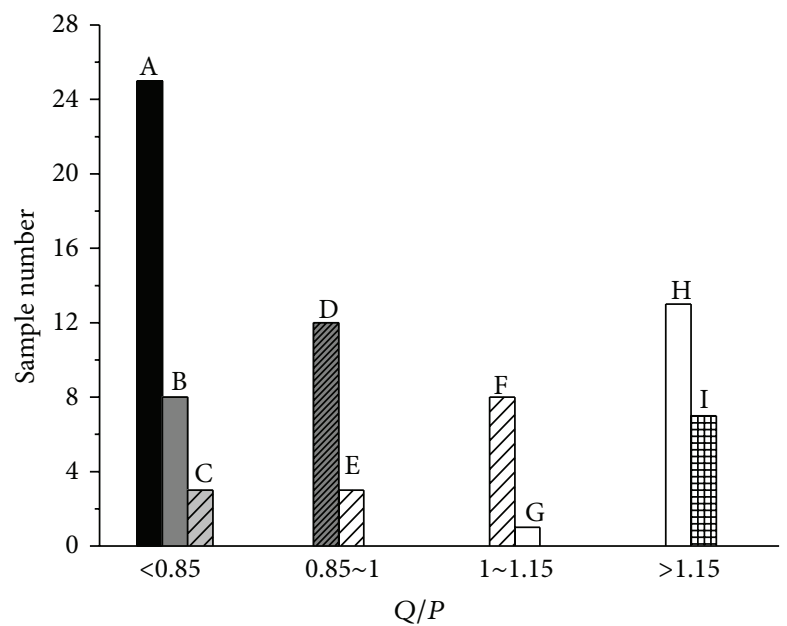

Figure 12: Histogram for piles with different defect classifications.

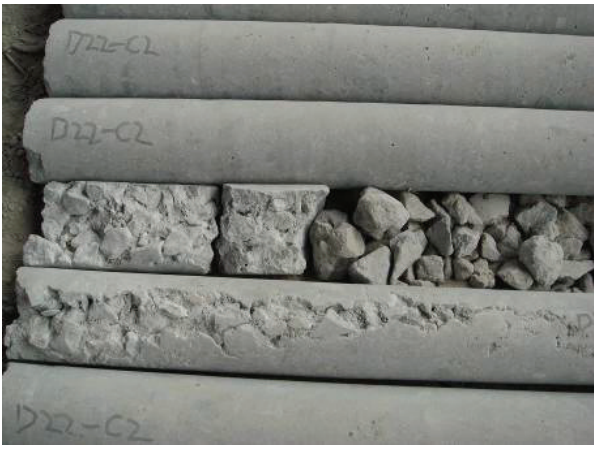

(a) $Q / P<0.85$

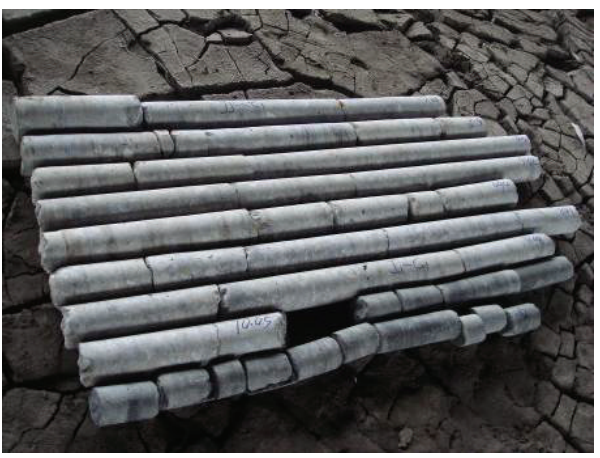

(c) $1<\mathrm{Q} / P<1.15$

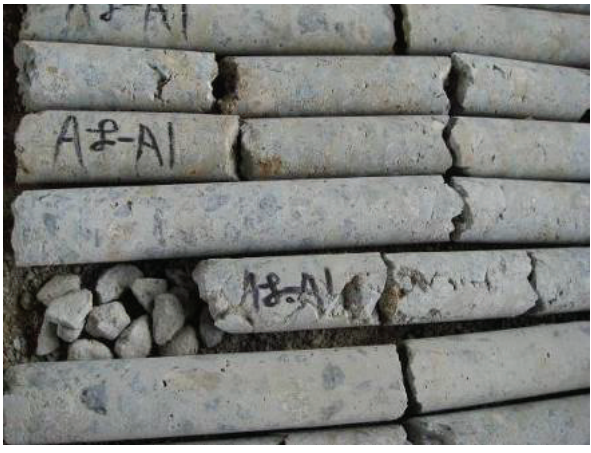

(b) $0.85<Q / P<1$

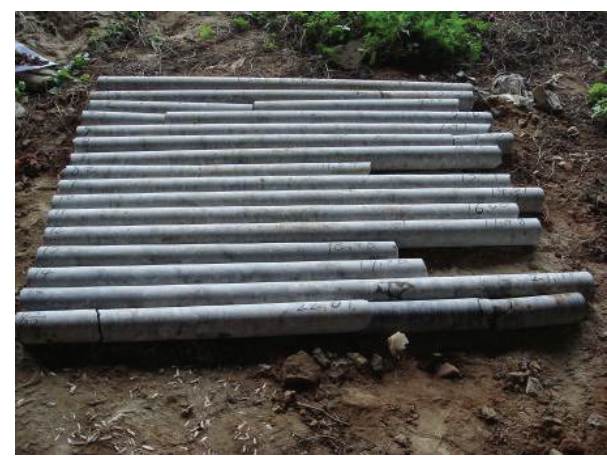

(d) $Q / P>1.15$

FIGURE 13: Pictures of typical core drilling samples.

\section{Acknowledgment}

The authors gratefully acknowledge the support of the Research Fund from Beijing Jiaotong University (Project no. 2014RC033).

\section{References}

[1] N. Q. Huy, "Literature review-quasi-static and dynamic pile load test," Primarily Report on Non-Static Pile Load Test, TU Delft, Delft, The Netherlands, 2010.
[2] Z. T. Lu, Z. L. Wang, and D. J. Liu, "Study on low-strain integrity testing of pipe-pile using the elastodynamic finite integration technique," International Journal for Numerical and Analytical Methods in Geomechanics, vol. 37, no. 5, pp. 536-550, 2013.

[3] S.-H. Ni, L. Lehmann, J.-J. Charng, and K.-F. Lo, "Low-strain integrity testing of drilled piles with high slenderness ratio," Computers and Geotechnics, vol. 33, no. 6-7, pp. 283-293, 2006.

[4] S.-H. Ni, K.-F. Lo, L. Lehmann, and Y.-H. Huang, "Timefrequency analyses of pile-integrity testing using wavelet transform," Computers and Geotechnics, vol. 35, no. 4, pp. 600-607, 2008. 
[5] ASTM International, "Standard test method for low strain impact integrity testing," ASTM D5882-07, ASTM International, West Conshohocken, Pa, USA, 2013.

[6] Australian Standard, "Standard piling-design and installation," Tech. Rep. AS2159-2009, 2010.

[7] Chinese Code, "Technical code for testing of building foundation piles," JGJ 106-2006, Chinese Code, 2006.

[8] GEO, "Foundation design and construction," GEO Publication 1/2006, Geotechnical Control Office, Hong Kong, 2006.

[9] A. G. Davis and C. S. Dumm, "From theory to field experience with the non-destructive vibration testing," Proceeding of Institution of Civil Engineers, Part 2, no. 57, pp. 571-593, 1974.

[10] L. Liang and J. Beim, "Effect of soil resistance on the low strain mobility response of piles using impulse transient response method," in Proceedings of the 8th International Conference on the Application of Stress Wave Theory to Piles, pp. 435-441, IOS Press, Lisbon, Portugal, September 2008.

[11] F. Rausche, "Non-destructive evaluation of deep foundations," in Proceedings of the 5th International Conference on Case Histories in Geotechnical Engineering, pp. 1-9, New York, NY, USA, April 2004.

[12] A. G. Davis, "The nondestructive impulse response test in North America: 1985-2001," NDT \& E International, vol. 36, no. 4, pp. 185-193, 2003.

[13] S. T. Liao and J. M. Roesset, "Dynamic response of intact piles to impulse loads," International Journal for Numerical and Analytical Methods in Geomechanics, vol. 21, no. 4, pp. 255-275, 1997.

[14] K. F. Lo, S. H. Ni, and Y. H. Huang, "Non-destructive test for pile beneath bridge in the time, frequency, and time-frequency domains using transient loading," Nonlinear Dynamics, vol. 62, no. 1-2, pp. 349-360, 2010.

[15] N. Massoudi and W. Teffera, "Non-destructive testing of piles using the low strain integrity method," in Proceedings of the 5th International Conference on Case Histories in Geotechnical Engineering, New York, NY, USA, April 2004.

[16] Chinese Code, "Code for design of ground base and foundation of highway bridges and culverts," JTG D63-2007, China Communications Press, Beijing, China, 2007.

[17] Y.-H. Huang and S.-H. Ni, "Experimental study for the evaluation of stress wave approaches on a group pile foundation," NDT \& E International, vol. 47, pp. 134-143, 2012. 


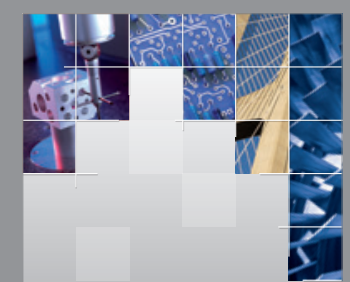

\section{Enfincering}
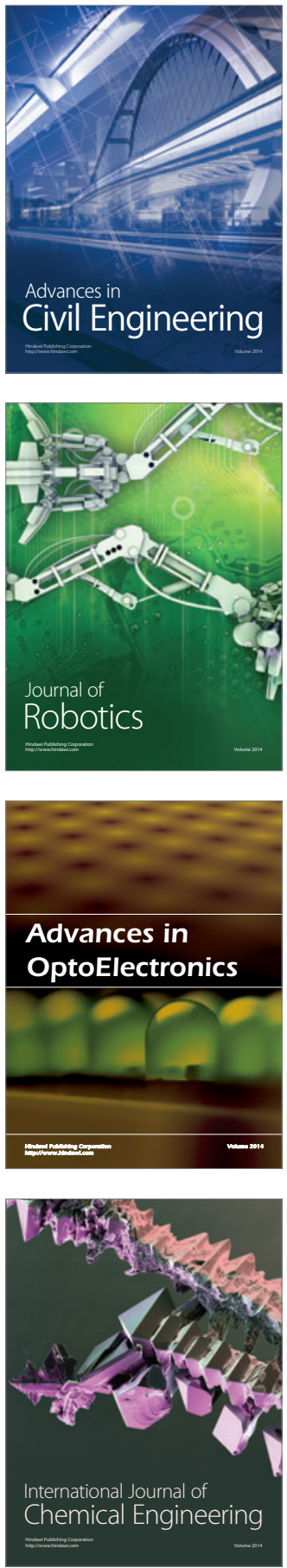

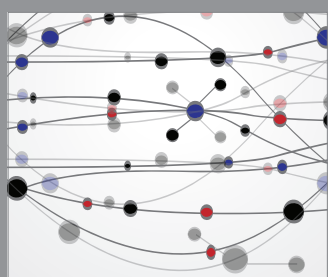

The Scientific World Journal

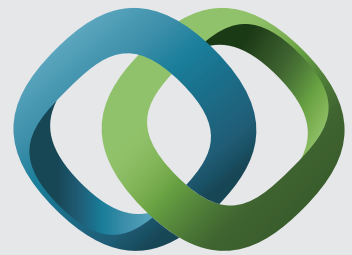

\section{Hindawi}

Submit your manuscripts at

http://www.hindawi.com
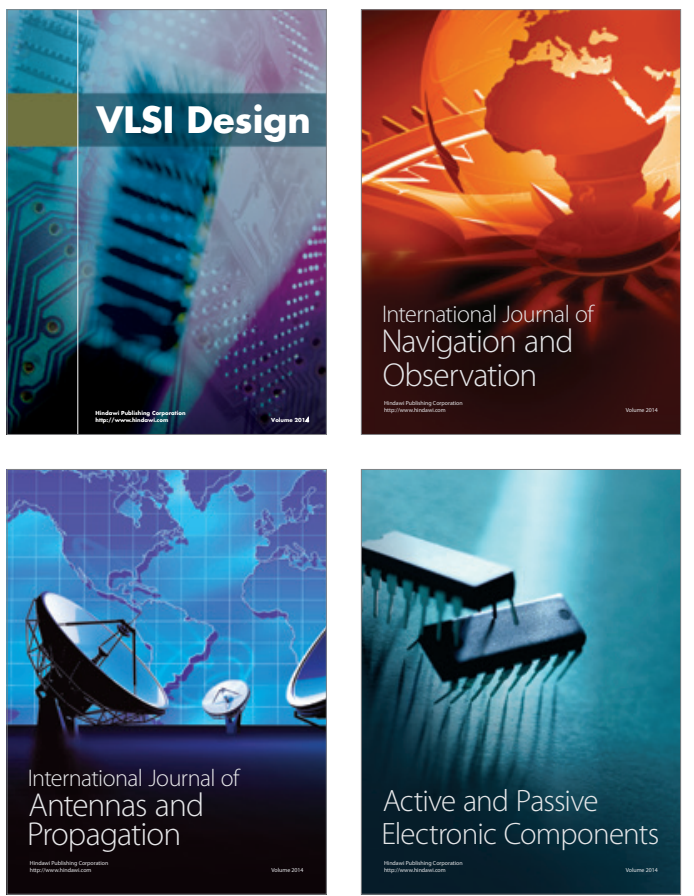
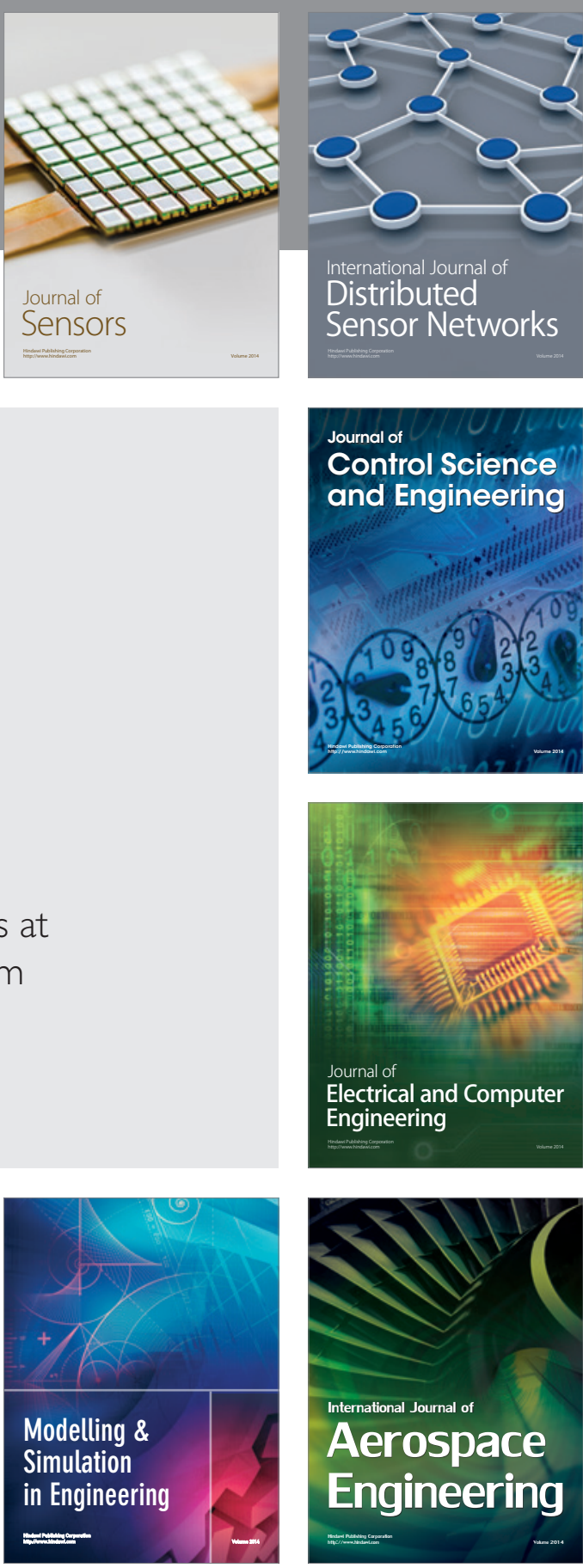

International Journal of

Distributed

Sensor Networks

Journal of

Control Science

and Engineering
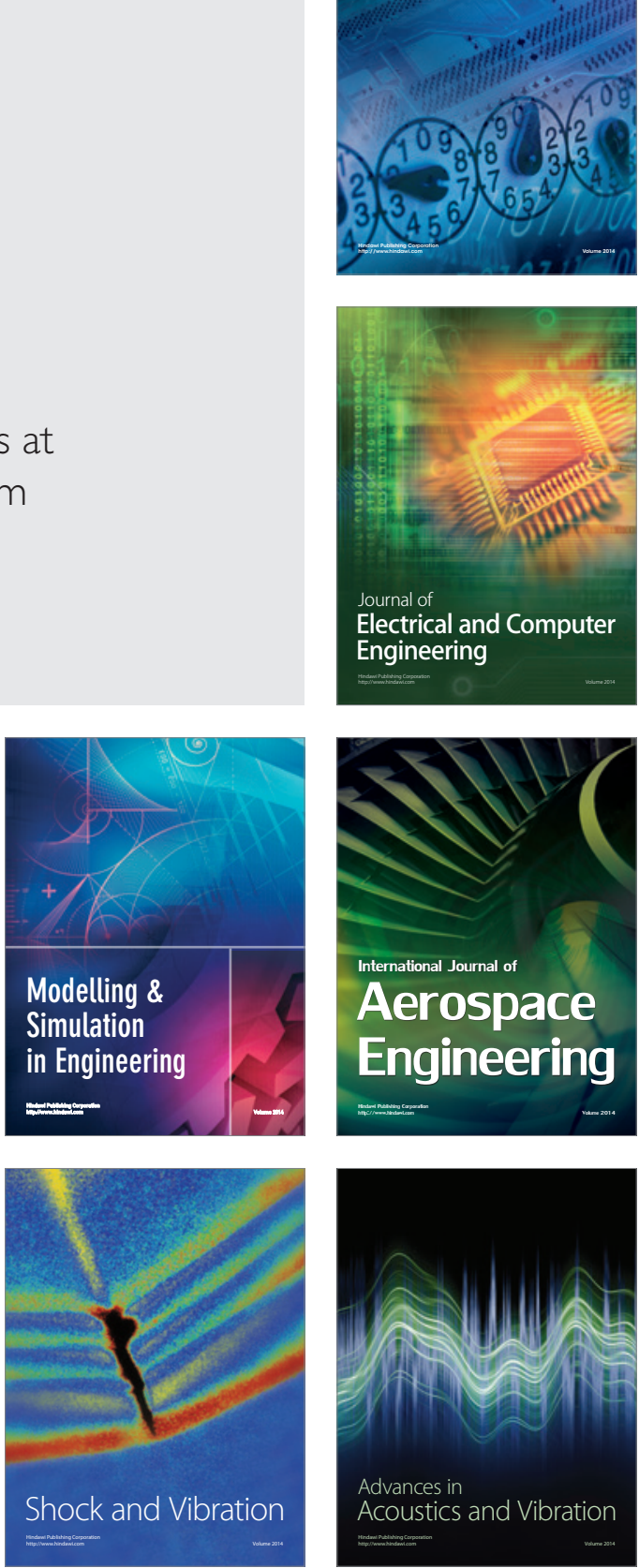